\section{LA-UR- $9 q-0 / 085$}

Approved for public release:

distribution is unlimited.
Titie: New Perspectives on the Damage Estimation for Buried Pipeline Systems due to Seismic Wave Propagation for the National Nuclear Security Administration of the U.S. Department of Energy under contract DE-AC52-06NA25396. By acceptance of this article, the publisher recognizes that the U.S. Government retains a nonexclusive, royalty-free license to publish or reproduce the published form of this contribution, or to allow others to do so, for U.S. Government purposes. Los Alamos National Laboratory requests that the publisher identify this anticle as work performed under the auspices of the U.S. Department of Energy. Los Alamos National Laboratory strongly supports academic freedom and a researcher's right to publish; as an institution, however, the Laboratory does not endorse the viewpoint of a publication or guarantee its technical correctness. 


\title{
New Perspectives on the Damage Estimation for Buried Pipeline Systems due to Seismic Wave Propagation
}

\author{
Omar Pineda-Porras ${ }^{1}$
}

${ }^{1}$ Post-Doctoral Research Associate, Energy and Infrastructure Analysis (D-4) - Earth \& Environmental Science (EES-11), Los Alamos National Laboratory, P.O. Box 1663, MS K575, Los Alamos NM 87545; Phone (505)665-6997; email: opp@lanl.gov

\begin{abstract}
Over the past three decades, seismic fragility formulations for buried pipeline systems have been developed following two tendencies: the use of earthquake damage scenarios from several pipeline systems to create general pipeline fragility functions; and, the use of damage scenarios from one pipeline system to create specific-system fragility functions. In this paper, the advantages and disadvantages of both tendencies are analyzed and discussed; in addition, a summary of what can be considered the new challenges for developing better pipeline seismic fragility formulations is discussed. The most important conclusion of this paper states that more efforts are needed to improve the estimation of transient ground strain -the main cause of pipeline damage due to seismic wave propagation; with relevant advances in that research field, new and better fragility formulations could be developed.
\end{abstract}

\section{INTRODUCTION}

There have been important advances in the seismic damage estimation for buried pipelines through the use of fragility formulations. A fragility formulation is a function or group of functions that relates damage with seismic intensity. In general, pipeline damage can be quantified as the number of pipe repairs per unit length of pipeline (e.g. repairs $/ \mathrm{km}$ ); the work of Trifunac and Todorovska (1999) is an exemption to this trend since they defined damage as the number of pipe repairs per area unit (repairs $/ \mathrm{km}^{2}$ ).

In pipeline fragility functions, seismic intensity can be represented by a diverse group of ground motion parameters. The most representative studies on pipeline fragilities are enlisted in Table 1; as it is observed, six seismic damage indicator parameters have been used as arguments in pipeline fragilities in those studies since 1975, which are: Modified Mercalli Intensity (MMI), Peak Ground Acceleration (PGA), Peak Ground Velocity (PGV), Peak Ground Displacement (PGD), Peak Ground Strain $\left(\varepsilon_{g}\right)$, and the novel parameter for very soft soils, $\mathrm{PGV}^{2} / \mathrm{PGA}$.

In several studies (e.g. O'Rourke, T.D. et al., 1998), it has been demonstrated that PGV has a stronger relationship with buried pipeline damage than MMI or PGA; this is mainly due to its relationship with transient ground strain $\left(\varepsilon_{g}\right)$, the believed main 
cause of damage in buried pipelines due to seismic wave propagation. The use of $\varepsilon_{g}$ as damage indicator in pipeline fragilities has not been very extended due to the difficulties to get accurate estimates of it; the fragility function proposed by O'Rourke and Deyoe (2004) is the only known case by the author. Recently, a novel parameter for pipeline damage estimation in soft soils has been proposed in terms of PGA and PGV: PGV²/PGA (Pineda and Ordaz, 2007).

From the six ground motion parameters that have been employed as damage predictors in pipeline fragilities, three of them $\left(\varepsilon_{g}, \mathrm{PGV}\right.$, and $\left.\mathrm{PGV}^{2} / \mathrm{PGA}\right)$ are analyzed in this paper. MMI and PGA are not included in this revision since it has been demonstrated that PGV is better damage predictor than those two parameters. PGD is not included in this analysis since it has not extensively been used as damage predictor in pipeline fragilities mainly due to the difficulties found in its calculation. The double integration of acceleration time histories and other processes like tapering, filtering, and correction of base line, could produce unreliable PGD estimates.

In the following two sections the theoretical basis for the use of PGV and PGV $2 / \mathrm{PGA}$ as pipeline damage predictors are presented, respectively. Since the main objective of this paper is to discuss the future challenges for developing pipeline fragilities, it is suggested that the interested readers look for further information on pipeline fragilities in the references shown in Table 1.

Table 1. References to Pipeline Fragility Functions Studies

\begin{tabular}{|l|c|c|c|c|c|c|}
\hline \multicolumn{1}{|c|}{ Reference } & MMI & PGA & PGV & PGD & $\varepsilon_{g}$ & PGV $/$ PGA \\
\hline Katayama et al (1975) & & $\mathrm{X}$ & & & & \\
\hline Isoyama and Katayama (1982) & & $\mathrm{X}$ & & & & \\
\hline Eguchi (1983) & $\mathrm{X}$ & & & & & \\
\hline Barenberg (1988) & & & $\mathrm{X}$ & & & \\
\hline Ballantyne et al. (1990) & $\mathrm{X}$ & & & & & \\
\hline Eguchi (1991) & $\mathrm{X}$ & & & & & \\
\hline ASCE-TLCEE (1991) & & $\mathrm{X}$ & & & & \\
\hline O'Rourke, T.D. et al. (1991) & $\mathrm{X}$ & & & & & \\
\hline Hamada (1991) & & $\mathrm{X}$ & & & & \\
\hline O'Rourke, M.J. and Ayala (1993) & & & $\mathrm{X}$ & & & \\
\hline Eidinger (1995) & & & $\mathrm{X}$ & & & \\
\hline Eidinger (1998) & & & $\mathrm{X}$ & & & \\
\hline O'Rourke, T.D. et al. (1998) & $\mathrm{X}$ & $\mathrm{X}$ & $\mathrm{X}$ & $\mathrm{X}$ & & \\
\hline Isoyama et al. (2000) & & $\mathrm{X}$ & $\mathrm{X}$ & & & \\
\hline ALA (2001) & & & $\mathrm{X}$ & & & \\
\hline Pineda and Ordaz (2003) & & & $\mathrm{X}$ & & & \\
\hline O'Rourke, M.J. and Deyoe (2004) & & & $\mathrm{X}$ & & $\mathrm{X}$ & \\
\hline Pineda and Ordaz (2007) & & & & & & \\
\hline
\end{tabular}




\section{ON THE USE OF PGV FOR BURIED PIPELINE DAMAGE ESTIMATION}

PGV has been widely used as damage indicator for buried pipelines due to its relationship with maximum ground strain $\varepsilon_{g}$ (compression or tension). Newmark (1967) proposed Equation 1 to assess $\varepsilon_{g}$ from the ratio between PGV and propagation velocity of seismic waves $(C)$. Equation 1 must be modified if the direction of analysis is not parallel to the direction of wave propagation.

$$
\varepsilon_{g}=\frac{P G V}{C}
$$

For body waves, since S-waves carry more energy, they are more dangerous than Pwaves for buried pipelines. If S-waves propagate parallel to the pipeline, $C$ is the apparent propagation velocity with respect to the ground surface. For surface waves, the axial effect of the Rayleigh waves is more important than the significantly less bending strains produced by Love waves. Rayleigh waves cause a retrograde elliptical motion in the ground particles and generate axial strains in the direction of wave propagation, which could significantly affect pipelines. $C$, for Rayleigh waves, is the phase velocity $C_{p h}$ and is quantified by a dispersion curve. $C_{p h}$ is a function of the wavelength $\lambda$ and of the frequency $f$ (Equation 2). O'Rourke and Liu (1999) recommend to calculate $C_{p h}$ for a wavelength equal to approximately four times the separation distance in order to obtain the maximum value of $\varepsilon_{g}$.

$$
C_{p h}=\lambda \cdot f
$$

Rigorously, transient ground strain can be estimated from displacement time histories through Equation 3, where $x$ is a space variable, and $\varepsilon(t)$ and $D(t)$ are ground strain and displacement time histories, respectively. In Equation 3, max represents the maximum of the expression between absolute value.

$$
\varepsilon_{g}=\max |\varepsilon(t)|=\max \left|\frac{\partial D(t)}{\partial x}\right|
$$

It is evident that if ground strain is the direct responsible of damage in buried pipelines, $\varepsilon_{g}$ is the optimum parameter for developing pipeline fragility formulations despite this fact, PGV, instead of $\varepsilon_{g}$, has been widely used as damage indicator mainly due to the following reasons: 1) The derivation process of $D(t)$ (Equation 3 ) with respect to a space variable $x$ implies that the seismic records, employed in the analysis, are referenced to an absolute time scale; this is a very significant limitation since only ground motion information from networks liked to the same time scale and located in the place of interest (e.g. the zone covered by a pipeline system) would be 
useful. 2) $D(t)$ is generally obtained through the double integration of acceleration time histories which produce loss of information due to the mathematical operations involved in the process. Operations like tapering, filtering and correction of base line could produce ambiguous results if the parameters involved in those operations are modified. 3) The high costs of installation and operation of seismic networks makes difficult the acquisition of seismic records (with the same time reference) due to the large extension usually covered by pipeline systems. 4) $\varepsilon_{g}$ can be easily computed with PGV by using Equation 1; there are techniques to obtain PGV values in zones where there is no instrumentation (e.g. attenuation laws) which makes easier its estimation for wide areas.

Though in numerous studies $\varepsilon_{g}$ has been estimated from PGV and $C$ with satisfactory results, the use of Equation 1 for estimating $\varepsilon_{g}$ in zones where particular soil conditions are found could lead to unexpected results. Singh et al (1997) analyzed ground strains at the Roma micro-array in Mexico City for four earthquakes. They concluded that Equation 1 could be used to estimate $\varepsilon_{g}$ by using a phase velocity of $0.6 \mathrm{~km} / \mathrm{sec}$ instead of the value of $C$ at the natural period of lake-bed sites, which is equal to $1.5 \mathrm{~km} / \mathrm{sec}$. The authors indicate that the discrepancy in the value of $C$ could be due to local heterogeneities within the array.

\section{PGV $^{2} /$ PGA AS SEISMIC DAMAGE PREDICTOR FOR PIPELINES LOCATED IN VERY SOFT SOILS - The 1985 Michoacan Earthquake Pipeline Damage Scenario}

The 1985 Michoacan earthquake affected severely the Mexico City's primary water system (MCWS) leaving almost 3.5 million people without water. A comprehensive recognition of the damage was done by Ayala and O'Rourke (1989), where three conclusions were presented: 1) the damage was mainly due to seismic wave propagation; 2) the accumulated ground subsidence in the Valley of Mexico could have increased the damage; and 3) the spatial location of the network in the lake zone, characterized by clay sediments, increased the damage to the system due to propagation of seismic waves.

The progress in the estimation of ground motion intensity in the Valley of Mexico due to Pacific coastal earthquakes -including the important site effects observed-, and the 1985 Michoacan earthquake damage scenario for the MCWS have contributed for the development of fragility formulations for buried pipelines. Pineda (2002) demonstrated that PGV has better correlation with damage in the primary water system in Mexico City than PGA. Pineda and Ordaz (2003) reanalyzed the damage data in the MCWS, due to the 1985 earthquake, and proposed a damage function in terms of the peak ground velocity (PGV). Pineda and Ordaz (2007) have proposed the parameter $\mathrm{PGV}^{2} / \mathrm{PGA}$ (PGA being the peak ground acceleration) as a damage indicator, which, according with their results, can be considered a better damage predictor than PGV alone. The results show a linear relationship between the repair rate and $\mathrm{PGV}^{2} / \mathrm{PGA}$ with a considerable reduction of uncertainty in comparison 
to the results previously presented in Pineda and Ordaz (2003). In both studies, the same technique to compute the respective fragility functions was used. Pineda and Ordaz (2009), following a similar method employed by Pineda and Ordaz (2007), analyzed the influence of ground subsidence in the 1985 damage scenario and proposed a fragility formulation in terms of $\mathrm{PGV}^{2} / \mathrm{PGA}$ - a parameter related to ground motion-for two levels of relative ground subsidence levels - a parameter related only to the ground-.

\section{FUTURE CHALLENGES FOR DEVELOPING ENHANCED PIPELINE FRAGILITIES}

Two of the most important challenges for developing better damage estimation tools are: 1) to minimize uncertainty in the damage estimation; and 2) to produce wideapplicability estimation tools, so more pipeline systems can be studied. Unfortunately, these two challenges could opposite each other mainly due to the two following tendencies: 1) Wide-applicability pipeline fragilities: This tendency consists of to use damage data from several pipeline systems in order to calculate wide-applicability pipeline fragilities. Most of the pipeline fragilities are developed by combining information from several damage scenarios. These fragilities have wide applicability since it could be employed to assess seismic damage in diverse pipeline systems; however, the use of damage data from pipeline systems affected by seismic wave propagation under different soil conditions could increase the uncertainty of the fragility models. 2) Specific-pipeline-system fragilities: This tendency consists of the creation of fragility formulations by using damage data for only one pipeline system. Though these fragility functions could be used only in pipeline systems with similar characteristics and ground motion environment, the damage estimation uncertainty could be much lesser than the uncertainty of wide-applicability pipeline fragilities.

By analyzing the most important fragility formulations proposed until now (Table 1); it has been observed that the damage-intensity relationship dispersion is still large when information from several pipeline systems is used to compute fragility formulations. In addition, it has been observed that for the cases of single-system fragility formulations, like those proposed for Mexico City (Pineda and Ordaz, 2003 and 2007) the dispersion has been reduced considerably. It suggests that the use of information for only one system could result in fragilities with controlled uncertainty. When damage scenarios, from several damage scenarios and pipeline systems, are used for creating fragility formulations, the composite damage-intensity data points could produce fragility curves that, if are used to assess damage in each particular system, under the same earthquake environment, could result in a wrong number of expected repairs. An example of this situation is described as follow: the fragility function proposed by ALA (2001) was used with the 1985 Michoacan earthquake to assess damage in the Mexico City's Water System; the results show a damage scenario with 2.7 times the actual number of pipe breaks and leaks observed after the 1985 event. Though the fragility proponed by ALA (2001) was created with damage data from the 1985 event, it can not predict the same amount of damage observed during that same event. This inconsistency can be solve by creating fragility curves for only one system, as it is explained further in this paper. 
In general, it has been observed that the dispersion of damage-intensity data points can be reduced if specific studies are developed for a specific pipeline system; however, the required amount of information to produce reliable fragility functions could be vast. For the case of Mexico City, three things contributed to find a better damage predictor for the Mexico City Water System in comparison to PGV alone: 1) the research advances made mainly after the 1985 earthquake that have contributed to better understand and measure seismic ground motion in Mexico City; for example, the PGV ground motion maps proposed by Pineda and Ordaz (2004) were used to compute the fragility functions proposed by Pineda and Ordaz (2003), and later for creating the $\mathrm{PGV}^{2} / \mathrm{PGA}$-based fragility functions of Pineda and Ordaz (2007). 2) The comprehensive damage scenario for the Mexico City's Water System, due to the 1985 earthquake, done by O'Rourke and Ayala (1989). And, 3) the linear fragility relationship proposed by Pineda and Ordaz (2007) that demonstrate that pipe repairs are directly related to $\mathrm{PGV}^{2} / \mathrm{PGA}$.

If there is not enough information for developing system-specific fragility functions with reduced correlation coefficient, like in the case the Mexico City's pipeline fragilities, it is suggested the use of the fragilities like the one proposed by O'Rourke and Deyoe (2004). The authors provide fragilities for both surface waves and body waves; considering that surface wave affect much more buried pipeline systems than body waves, the use of these fragilities will make more reliable the estimation of damage if seismic wave type is considered in the analysis.

An important challenge is the creation of fragility systems including the effects of phenomena not related to earthquakes that could influence of the seismic response of the pipeline system. The phenomena could be soil-related like soil softness, ground subsidence, liquefaction, and other soil conditions that could modify the relationship between seismic intensity and pipeline damage. Other phenomena could be related to the pipeline itself, like pipe corrosion, type of joint, diameter, and material.

The use of PGV for pipeline damage estimation must be carefully analyzed considering the particular soil conditions of the site where the studied pipeline system is located. In sites where soft soil is present, the estimation of maximum ground strain through PGV and $C$ could lead to overestimated values. Though $\mathrm{PGV}^{2} / \mathrm{PGA}$ has been successfully used for the creation of fragility formulations for Mexico City, the use of this parameter must be limited to places with similar soil conditions observed in the city.

Another important challenge for the creation of new fragility curves is the reduction of uncertainties in the damage estimation for pipelines. Uncertainties related to the creation of new fragilities could be increased by the damage scenario data used in the analysis; inaccurate damage estimates, location of pipe breaks and leaks, information on pipe types, state of pre-earthquake pipe condition, pipe joints, are among the uncertainty contributors. Uncertainties related to the ground motion estimation could have many sources depending on the sources of information used for the analysis. 
Seismic records, attenuation laws, transfer functions, ground motion simulations, time signal processing (tapering, baseline correction, etc.), mathematical procedures (e.g. interpolation, extrapolation, curve fitting, etc.). The reduction of uncertainty in the estimation of maximum ground strain through Equation 1 could be addressed with the analysis of dispersion curves for the area covered by the pipeline system in order to obtain reliable values of $C$. The comparison of calculated values of $\varepsilon_{g}$ from seismic records and those obtained with Equation 1, could help to identify if PGV is an appropriate damage predictor for pipelines, or if a adjust factor is needed in Equation 1 to get accurate estimates of $\varepsilon_{g}$.

For the damage estimation in pipeline systems where damage scenarios and/or ground motion estimates are not available, the best way to choose an appropriate fragility function is to look for the one that best fit the scenario in study; that means, to choose a fragility created under similar circumstances: pipeline characteristics (material, diameter, joint type, etc), soil conditions (stiffness, ground subsidence), seismic environment (seismic wave types), etc. If there is a group of fragilities, a new composite fragility curves can be used through the use of weights for each function; weight can be chosen following expert opinion.

\section{CONCLUSIONS}

The most important conclusion of this paper is that more efforts are needed to improve the estimation of transient ground strain $\left(\varepsilon_{g}\right)$ due to seismic wave propagation; with relevant advances in that subject, new and better fragility formulation could be proposed since it is the direct responsible of pipeline damage due to seismic wave propagation. Due to the limitations for the estimation of $\varepsilon_{g}$, the use other damage indicators for buried pipelines could be appropriate (e.g. PGV and $\mathrm{PGV}^{2} / \mathrm{PGA}$ ); however, a careful analysis of soil conditions must be done to ensure that the selected seismic parameter is appropriate for the damage analysis. It is expected that future fragility formulations provide more reliable damage estimates and contribute for creating pre and post-earthquake plans aimed to reduce the serviceability interruption of any buried pipeline system.

\section{REFERENCES}

American Lifelines Alliance, ALA (2001) Seismic Fragility Formulations for Water Systems, American Society of Civil Engineers \& Federal Emergency Management Agency.

ASCE/TCLEE (1991) Seismic loss estimation for a hypothetical water system, ASCE/TCLEE Monograph No.2, C.E. Taylor (ed.). 
Ayala, G. and O'Rourke, M. (1989) Effects of the 1985 Michoacan earthquake on water systems and other buried lifelines in Mexico, Technical Report NCEER-890009, Multidisciplinary Center for Earthquake Engineering Research, New York.

Ballantyne, D.B., Berg, E., Kennedy, J., Reneau, R., and Wu, D. (1990) "Earthquake loss estimation modeling for the Seattle water system: report to US Geological Survey under Grant 14-08-0001-G1526," Technical Report, Kennedy/Jenks/Chilton, Federal Way, WA.

Barenberg, M.E. (1988). "Correlation of pipeline damage with ground motions." Journal of Geotechnical Engineering, ASCE, June, 114 (6), 706-711.

Eidinger, J. (1998). "Water distribution system" In: Anshel J. Schiff (ed.) The Loma Prieta, Californai, Earthquake of October 17, 1989 - Lifelines. USGS Professional Paper 1552-A, US Government Printing Office, Washington, A63-A78.

Eidinger, J., Maison, B, Lee, D. and Lau, B. (1995) "East Bay Municipal District water distribution damage in 1989 Loma Prieta earthquake". Proceedings of the Fourth US Conference on Lifeline Earthquake Engineering, ASCE, TCLEE, Monograph No. 6, 240-247

Eguchi, R.T. (1983) "Seismic vulnerability models for underground pipes," Proceedings of Earthquake Behavior and Safety of Oil and Gas Storage Facilities, Buried Pipelines and Equipment, PVP-77, ASME, New York, June, 368-373.

Eguchi, R.T. (1991) "Seismic hazard input for lifeline systems," Structural Safety, 10, 193 198.

Hamada, M. (1991). "Estimation of earthquake damage to lifeline systems in Japan," Proceedings of the Third Japan-US Workshop on Earthquake Resistant Design of Lifeline Facilities and Countermeasures for Soil Liquefaction, San Francisco, CA, December 17-19, 1990, Technical Report NCEER-91-0001, NCEER, State University of New York at Buffalo, Buffalo, NY, 5-22.

Isoyama, R. \& Katayama, T. (1982). "Reliability evaluation of water supply systems during earthquakes," Report of the Institute of Industrial Science, University of Tokyo, 30 (1) (Serial No. 194).

Isoyama, R., Ishida, E., Yune, K. and Shirozu, T. (2000) "Seismic damage estimation procedure for water supply pipelines," Proceedings of the Twelfth World Conference on Earthquake Engineering, CD-ROM Paper No. 1762, 8pp.

Katayama, T., Kubo, K. and Sato, N. (1975) "Earthquake damage to water and gas distribution systems," Proceedings of the U.S. National Conference on Earthquake Engineering., EERI, Oakland, CA, 396-405.

Newmark, N.M. (1967) "Problems in wave propagation in soil and rocks", Proceedings of the International Symposium on Wave Propagation and Dynamic Properties of Earth Materials, University of New Mexico Press. 
O'Rourke, M.J. \& Ayala, G. (1993). "Pipeline damage due to wave propagation." Journal of Geotechnical Engineering. ASCE. 119 (9), 1490-1498.

O'Rourke, M. and X. Liu, (1999) Response of buried pipelines subject to earthquake effects, Monograph Series No 3, Multidisciplinary Center for Earthquake Engineering Research, Buffalo, New York.

O'Rourke, M., and Deyoe, E., (2004) "Seismic damage to segmented buried pipe", Earthquake Spectra, (20) 4, 1167-1183.

O'Rourke, T.D., Stewart, H.E., Gowdy, T.E. and Pease, J.W. (1991). "Lifeline and geotechnical aspects of the 1989 Loma Prieta earthquake," Proceedings of the Second International Conference on Recent Advances in Geotechnical Earthquake Engineering and Soil Dynamics, St. Louis, MO, 1601-1612.

O'Rourke, T.D., Toprak, S. and Sano, Y. (1998) "Factors affecting water supply damage caused by the Northridge earthquake." Proceedings of the Sixth US National Conference on Earthquake Engineering.

Pineda O. (2002) Estimación de daño sismico en la red primaria de distribución de agua potable del Distrito Federal. Master of Engineering Thesis. Instituto de Ingeniería, UNAM; Distrito Federal, México.

Pineda, O. and M. Ordaz, (2003) "Seismic vulnerability function for high-diameter buried pipelines: Mexico City's primary water system case", 2003 ASCE International Conference on Pipeline Engineering and Construction, American Society of Civil Engineers, Baltimore, USA.

Pineda, O. and M. Ordaz, (2004) Peak ground velocity maps for Mexico City, Journal of Earthquake Engineering, Mexican Society of Earthquake Engineering, No. 71, July - December 2004. In spanish.

Pineda, O., and Ordaz, M. (2007) "A new seismic intensity parameter to estimate damage in buried pipelines due to seismic wave propagation", Journal of Earthquake Engineering, (11) 773-786.

Pineda, O., and Ordaz, M. (2009) "Seismic fragility formulation for segmented buried pipeline systems including the impact of differential ground subsidence", Journal of Earthquake Engineering. Sent for review.

Singh, S.K., Santoyo, M., Bodin, P. and Gomberg, J. (1997) "Dynamic deformations of shallow sediments in the Valley of Mexico. Part II: single-station estimates", Bull. Seism. Soc. Am. 87, 540-550.

Trifunac, M.D. and Todorovska, M.I. (1999) "Reduction of structural damage by nonlinear soil response," Journal of Structural Engineering, 125 (1), 89-97. 